J. Lake Sci. (湖泊科学), 2018, 30(5): 1271-1283

DOI 10. 18307/2018. 0510

(c) 2018 by Journal of Lake Sciences

\title{
城市河流沉积物中氮素与好氧甲烷氧化菌群落特征响应关系
}

\author{
刘 洋 $^{1,2}$, 陈永娟 ${ }^{1}$, 王晓燕 ${ }^{1,3 * *}$, 许康利 ${ }^{1}$ \\ (1: 首都师范大学资源环境与旅游学院, 北京 100048$)$ \\ (2: 中国水利水电科学研究院, 北京 100038$)$ \\ (3: 首都师范大学首都圈水环境研究中心,北京 100048)
}

摘 要: 由于人类活动的影响大量未经处理的废污水汇人城市河流, 高浓度的污染物影响了河流中微生物对生物地球化 学物质迁移和转化的介导作用. 本文选取典型的城市河流——北运河作为研究区域, 分析了北运河沉积物中氮素形态以 及含量的空间和季节差异性, 并结合克隆文库分子生物学的方法, 探讨了氮素形态和含量的差异对好氧甲烷氧化菌 (aerobic methane-oxidizing microorganisms, MOB) 群落特征的影响. 结果表明: 北运河沉积物中铵态氮 $\left(\mathrm{NH}_{4}^{+}-\mathrm{N}\right)$ 为氮素的主 要存在形态, 存在显著的空间差异, 其含量在下游显著高于上游, 但季节差异不显著. $\mathrm{NH}_{4}^{+} \mathrm{-N}$ 含量的空间差异对 MOB 的 群落结构和群落分布有显著影响, 对群落多样性影响不显著. $\mathrm{NH}_{4}^{+}-\mathrm{N}$ 含量的空间分布特征与 MOB 的群落聚类特征一致, $\mathrm{NH}_{4}^{+}-\mathrm{N}$ 对 MOB 群落分布的影响显著高于其他形态的氮素, 其含量越高, 则与 MOB 群落分布的响应关系越紧密. 北运河 中 $\mathrm{NH}_{4}^{+}-\mathrm{N}$ 的来源影响了沉积物中 MOB 的主要来源, $\mathrm{MOB}$ 高同源性菌群的来源与 $\mathrm{NH}_{4}^{+}-\mathrm{N}$ 等主要污染物的来源一致. 沉积 物中 MOB 物种之间联系的紧密程度依赖于氮素的主要存在形态及其含量水平. $\mathrm{NH}_{4}^{+}-\mathrm{N}$ 含量较高的下游沉积物中微生物 彼此之间关系及集聚程度更强, 受外界环境变化的干扰程度更强, 受人类活动引起环境变化的敏感程度更高. 城市河流 中氮素的形态和含量差异对甲烷的氧化过程有显著影响. 探究城市河流沉积物中高含量的 $\mathrm{NH}_{4}^{+}-\mathrm{N}$ 对甲烷产生及消耗的 影响过程是控制河流温室气体排放的关键.

关键词: 沉积物; 好氧甲烷氧化菌; 铵态氮; 群落结构;系统发育;共存关系;环境因子

\section{The response relationship between nitrogen and aerobic methanotrophs in sediment of urban river, Beijing, China}

\author{
LIU Yang ${ }^{1,2}$, CHEN Yongjuan ${ }^{1}$, WANG Xiaoyan ${ }^{1,3 * *} \&$ XU Kangli ${ }^{1}$ \\ (1: College of Resources, Environment and Tourism, Capital Normal University, Beijing 100048, P.R.China) \\ (2: China Institute of Water Resources and Hydropower Research, Beijing 100038, P.R.China) \\ (3: Research Center of Aquatic Environment in the Capital Region, Capital Normal University, Beijing 100048, P.R.China)
}

Abstract : Stream ecosystems are the main receivers of nutrient and organic carbon exported from terrestrial ecosystems. Stream ecosystems are profoundly influenced by the land used in the surrounding area. Anthropogenic activities increase the amount of nutrient and organic carbon in both stream and benthic biofilms, which are closely related to differences in the aerobic methane-oxidizing microorganisms ( MOB) bacteria microbial communities. We studied MOB bacteria microbial communities in the North Canal, Beijing, China. The results showed that the main form of nitrogen was ammonium nitrogen $\left(\mathrm{NH}_{4}^{+}-\mathrm{N}\right)$ in the North Canal. There are not any significant differences of the $\mathrm{NH}_{4}^{+}$- $\mathrm{N}$ between summer and winter, whereas there are significant differences between midstream and downstream. Results of heatmap analysis were closely related to the difference of the $\mathrm{NH}_{4}^{+}$- $\mathrm{N}$ in spatial. Phylogenetic analysis indicated that most of the cloned $p m o A$ sequences in the North Canal were similar to those sequences from activated sludge and

* 北京市自然科学基金委员会-北京市教育委员会联合资助项目 (KZ20180028047)、科技创新服务能力建设-基本科 研业务费(科研类)（025185305000/149）、国家自然科学基金项目(41271495) 和国家水体污染控制与治理科技重 大专项 (2009ZX07209-001-02) 联合资助. 2017-12-12 收稿; 2018-02-04 收修改稿. 刘洋 (1988 ) , 女, 硕士; E-mail: liuyanglearn@163.com.

** 通信作者;E-mail: wangxy@ cnu.edu.cn. 
wastewater. The effect of nitrogen on MOB bacteria in the North Canal mainly depends on the main form of nitrogen and the source of pollutants. Moreover, MOB bacteria in downstream of the North Canal, had a more closer and modular microbial network than midstream, where bacteria communities with tightly connected species had proven to be more vulnerable and sensitive to various disturbances.

Keywords: Sediment; aerobic methane-oxidizing microorganisms; ammonium nitrogen; community structure; phylogeny; co-occurrence network; environmental factors

河流是全球碳循环的主要输送通道, 是陆地有机质参与生物地球化学循环的重要场所 ${ }^{[1]}$, 其水一气界 面二氧化碳与甲烷的排放构成全球碳循环的重要环节 ${ }^{[2]}$. 全球河流每年向大气排放 $1.5 \sim 26.8 \mathrm{Tg}$ 的甲烷, 其 对全球气候变暖的贡献不容小视 ${ }^{[3-4]}$. 甲烷在沉积物一水界面向水体扩散时,约 33\% 99\% 的甲烷会被甲烷 氧化菌的氧化作用消耗. 好氧甲烷氧化菌 (MOB) 以甲烷作为唯一的碳源, 能将 $90 \%$ 由产甲烷菌产生的甲烷 氧化 ${ }^{[3-4]}$.

由于人类活动的影响, 大量未经处理的生活污水、工业废水及农田化肥等含有大量有机质和氮素的污 水汇人河流, 导致河流中氮素、溶解态有机碳与溶解态无机碳之比及氮磷比升高, 对河流中微生物群落结构 产生影响 ${ }^{[5-8]}$. 其中, 外源氮对 MOB 氧化作用的影响主要依赖环境中氮的存在形态 ${ }^{[9]}$, 输人氮形态和浓度水 平不同对甲烷氧化过程的影响也不同 ${ }^{[10]}$. 普遍认为铵态氮 $\left(\mathrm{NH}_{4}^{+}-\mathrm{N}\right)$ 和硝态氮 $\left(\mathrm{NO}_{3}^{-}-\mathrm{N}\right)$ 均对亚硝酸盐还原性 厌氧甲烷氧化菌 $(\mathrm{N}-\mathrm{DAMO})$ 的氧化有抑制作用 ${ }^{[11]}, \mathrm{NH}_{4}^{+}-\mathrm{N}$ 对 $\mathrm{MOB}$ 氧化率的抑制性高于 $\mathrm{NO}_{3}^{-}-\mathrm{N}$ 对甲烷氧化 作用的抑制性 ${ }^{[12]}$. $\mathrm{NH}_{4}^{+}$与甲烷有相似的分子结构, 通过竞争甲烷单加氧酶系统相同的位点或降低甲烷氧化 酶活性, 从而抑制 N-DAMO 细菌的氧化作用 ${ }^{[13]}$. 外源氮素对 MOB 氧化作用的影响主要依赖于氮素的浓度 水平, 较高浓度的 $\mathrm{NH}_{4}^{+}-\mathrm{N}$ 对 $\mathrm{MOB}$ 甲烷氧化率的抑制性高于低浓度 $\mathrm{NH}_{4}^{+}-\mathrm{N}$ 的抑制性 ${ }^{[12-13]}$ 目前氮素形态及其 浓度对甲烷氧化作用的研究主要集中于农田土壤不同施肥状态下甲烷氧化微生物的群落特征、室内模拟不 同氮素形态和不同浓度对甲烷氧化的影响等, 而对于人类活动干扰程度及污染程度强的城市河流中氮素形 态和浓度差异对 MOB 群落特征影响的研究还明显不足.

北运河作为北京市主要的泄洪排污河道, 流经北京市人类活动最频繁的东部和北部地区, 受到人类活 动干扰大 ${ }^{[14]}$. 水质污染严重, 主要污染物为氮、磷和耗氧有机物, 其中超过 $50 \%$ 的氮、磷和耗氧有机物来自 未经处理的生活污水及农业灌溉径流的汇人 ${ }^{[15]}$. 北运河的排水河流主要有清河、坝河、通惠河、凉水河 4 大 排水河道, 其中清河中有肖家河和清河 2 座污水处理厂; 坝河主要接纳北小河和酒仙桥 2 座污水处理厂退 水; 通惠河是城区雨水管网的排水河道, 接纳高碑店污水处理厂退水; 凉水河主要接纳方庄酒厂、吴家村、卢 沟桥、小红门和亦庄开发区 5 座污水处理厂退水, 凉水河是 4 大排水河道中接纳污水处理厂最多、受污水处 理厂退水影响最大的支流, 其中仍有未经处理的污水及氮磷处理效率低的污水处理厂的出水汇人河道 ${ }^{[14]}$. 未经处理的工农业废水、城市生活污水及污水处理厂退水的汇人导致北运河水体中 $\mathrm{NH}_{4}^{+}-\mathrm{N}$ 严重超标, 河流 水体的 $\mathrm{NH}_{4}^{+}-\mathrm{N}$ 浓度已经达到地表水 $\mathrm{V}$ 类水质标准的 7.25 倍 ${ }^{[15-16]}$. 河道水流缓慢导致沉积物大量淤积, 而污 染物质的沉降、吸附使得沉积物成为内源污染源 ${ }^{[15,17]}$. 北京市经济的发展和人口的增长使北运河水体受到 严重污染,已经成为北京市水质最差的城市河流 ${ }^{[18]}$.

北运河中浓度较高的 $\mathrm{NH}_{4}^{+}-\mathrm{N}$ 是否存在空间及季节差异性以及沉积物中氮素的主要存在形态和浓度的 变化是否会对 MOB 群落特征产生影响是本文探讨的主要问题. 本文选取北京市主要城市河流一一北运河 作为研究区域, 采用克隆文库的方法, 通过分析不同季节、不同空间样点沉积物中氮素形态及浓度的差异 性, 探究氮素形态和浓度的不同对 MOB 群落分布、系统发育树及种间共存现关系的影响, 进一步明确氮素 的存在形态及其浓度水平对微生物群落特征及其氧化作用的影响. 该研究可以为控制城市河流中甲烷气体 的释放提供科学依据, 为进一步解释河流及湖泊富营养化与气候变化的联系及可能具有的反馈效应提供理 论基础.

\section{1 材料与方法}

\section{1 样品采集}

采样点主要布设在北运河北京段. 如图 1 所示, 共设置 7 个采样点, 其中北运河北京段的中游布设 $1^{\# 、}$ 
$2^{\#}$ 和 $3^{\#}$ 样点, 下游布设 $4^{\#} 、 5^{\#} 、 6^{\#}$ 和 $7^{\#}$ 样点. 分别于 2016 年 1 月和 2016 年 7 月使用抓泥斗采集底泥 $(0 \sim 5$ $\mathrm{cm})$ 样品约 $1 \mathrm{~kg}$.

样品储存于聚氯乙烯塑料瓶 $\left(-4^{\circ} \mathrm{C}\right)$ 中, $24 \mathrm{~h}$ 内运回实验室. 所有样品均分为两部分: 一部分用冷冻干 燥机 (Alpha 1-2 LD plus; Martin Christ, Germany) 冻干, 研磨过 200 目篮后用于理化分析; 另一部分放人 $-80^{\circ} \mathrm{C}$ 超低温冰箱保存, 用于后续分子生物学指标测定.

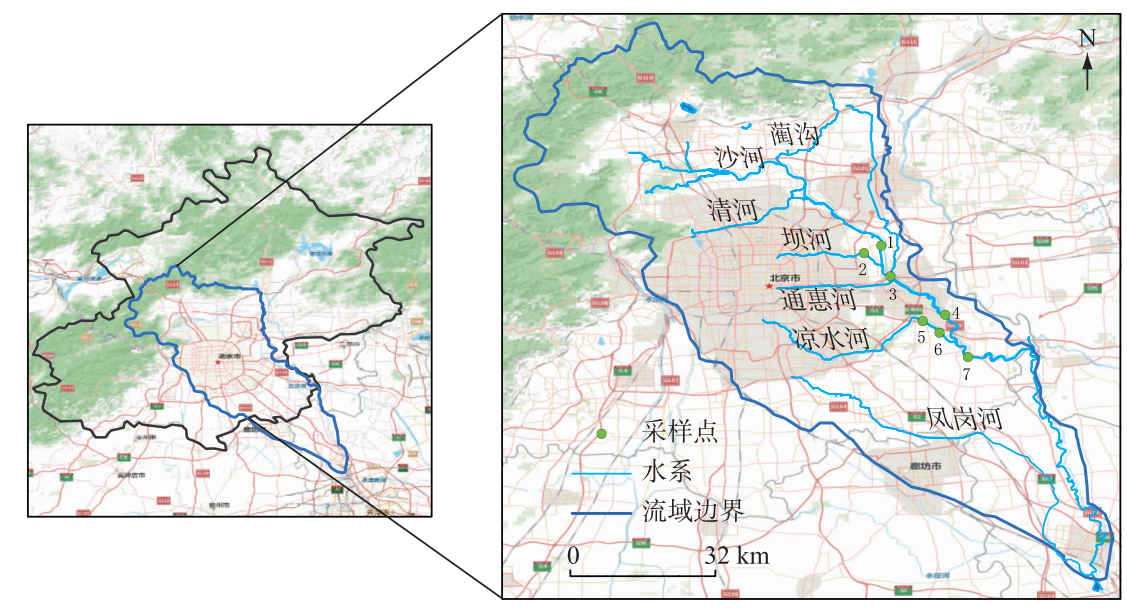

图 1 北运河采样点分布

Fig.1 Distribution of sampling sites in the North Canal

\section{2 样品理化分析}

温度 $(\mathrm{T}) 、 \mathrm{pH}$ 、溶解氧 $(\mathrm{DO})$ ）、盐度 (Salinity) 等水质指标使用多参数水质仪 (HYDROLABMS5) ( HACH, 美国) 现场测定. 其他理化指标依照《土壤理化分析 (第 5 版)》的方法进行测定 ${ }^{[19]}$. 沉积物中 $\mathrm{NH}_{4}^{+}-\mathrm{N} 、 \mathrm{NO}_{3}^{-}-\mathrm{N}$ 、 亚硝态氮 $\left(\mathrm{NO}_{2}^{-}-\mathrm{N}\right)$ 和总磷 $(\mathrm{TP})$, 用 $2 \mathrm{~mol} / \mathrm{L} \mathrm{KCl}$ 溶液浸提, 浸提悬浮液离心过滤, 使用 FIASTAR 5000 连续流 动进样分析仪 (FOSS, 丹麦) 测定; 总有机碳 (TOC) 使用总有机碳分析仪测定 (Liqui TOC II 德国) ; 总氮 (TN) 按照凯式定氮的方法使用凯氏定氮仪 (KDY-9830) 测定, 总溶解性固体 (TDS) 采用 TDS11 总溶解性固 体检测仪测定 (HANNA, 意大利).

\subsection{DNA 提取和 $p m o A$ 基因 PCR 扩增}

沉积物样品 DNA 使用 Power Soil DNA kit(Mo Bio Laboratories, Carlsbad, California, USA) 试剂盒, 依据 说明书提取. MOB 的 $p m o A$ 基因 PCR 扩增反应体系为: DNA 模板 $10 \mu \mathrm{l}$,前后引物各 $2 \mu \mathrm{l}, 2 \times \mathrm{Taq}$ PCR Master Mix (天根生化科技, 北京) $25 \mu \mathrm{l}$, 加蒸馏水 $\left(\mathrm{ddH}_{2} \mathrm{O}\right)$ 到总体积为 $50 \mu \mathrm{l}$. MOB 的 $p m o A$ 基因 PCR 扩增引物为 A189F ( 5'-GGNGACTGGGACTTCTGG-3') 和 Mb661R ( 5'-GGTAARGACGTTGCNCCGG-3'), PCR 扩增的主要 温度程序为: $94^{\circ} \mathrm{C}$ 预变性 $5 \mathrm{~min} ; 94^{\circ} \mathrm{C}$ 变性 $45 \mathrm{~s}, 56^{\circ} \mathrm{C}$ 退火 $60 \mathrm{~s} ; 72^{\circ} \mathrm{C}$ 延伸 $60 \mathrm{~s}$, 共 30 个循环; 最终 $72^{\circ} \mathrm{C}$ 延伸 $60 \mathrm{~s}^{[20]}$. 每个样品做两组平行取平均值, 扩增效率为 $100 \%$, 相关系数为 0.99 .

\section{4 数据分析}

使用 MOTHUR 软件以 $2 \%$ 的差异度划分独立操作单元 (operational taxonomic unit, OTU), 计算 Shannon 多样性指数、Simpson 指数和 Chao1 指数 ${ }^{[21]}$. 采用 MEGA 4 软件 ${ }^{[22]}$ 以邻位相连法 (Neighbor-Joining) 构建系统 发育树. 通过 STAMP 软件 ${ }^{[23]}$ 基于 $T$ 检验方法计算两样本之间的差异显著性. 使用 R 3.3.2 的 psych package

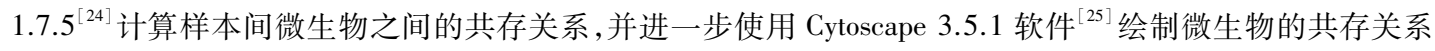
网络图. 采用R 3.3.2 软件的 Vegan package 2.4 ${ }^{[26]}$ 用于元余分析 (RDA). 采用 SPSS (PASW statistics 18.0) 软 件对理化数据进行统计分析. 


\section{2 结果与讨论}

\section{1 水体和沉积物理化指标}

北运河中游和下游水体及沉积物理化指标测定结果如表 1 所示, 其中 T、pH 值、DO 浓度和 TDS 浓度为 水质参数, $\mathrm{NO}_{3}^{-}-\mathrm{N} 、 \mathrm{NO}_{2}^{-}-\mathrm{N} 、 \mathrm{NH}_{4}^{+}-\mathrm{N} 、 \mathrm{TOC} 、 \mathrm{TN}$ 和 $\mathrm{TP}$ 含量为沉积物中的营养盐参数.

表 1 北运河中游和下游水体及沉积物中营养盐变化 (平均值+标准差)

Tab.1 Nutrient variations in water and sediment of midstream sites and downstream sites in the North Canal (Means \pm SD)

\begin{tabular}{|c|c|c|c|c|}
\hline \multirow{2}{*}{ 理化参数 } & \multicolumn{2}{|c|}{ 中游 } & \multicolumn{2}{|c|}{ 下游 } \\
\hline & 夏季 & 冬季 & 夏季 & 冬季 \\
\hline $\mathrm{T} /{ }^{\circ} \mathrm{C}$ & $30.17 \pm 0.45$ & $4.97 \pm 0.92$ & $31.95 \pm 0.26$ & $6.33 \pm 0.41$ \\
\hline $\mathrm{pH}$ & $7.90 \pm 0.10$ & $7.47 \pm 0.52$ & $8.15 \pm 0.11$ & $7.13 \pm 0.26$ \\
\hline $\mathrm{DO} /(\mathrm{mg} / \mathrm{L})$ & $0.49 \pm 0.11$ & $2.84 \pm 1.13$ & $1.96 \pm 0.29$ & $1.36 \pm 0.57$ \\
\hline TDS/ ( mg/L) & $408.00 \pm 15.52$ & $418.00 \pm 46.69$ & $577.25 \pm 12.29$ & $539.00 \pm 54.71$ \\
\hline Salinity & $0.5 \pm 0$ & $0.6 \pm 0.0001$ & $0.7 \pm 0$ & $0.73 \pm 0.15$ \\
\hline $\mathrm{NO}_{2}^{-}-\mathrm{N} /(\mathrm{mg} / \mathrm{kg})$ & $0.015 \pm 0.01$ & $0.018 \pm 0.004$ & $0.012 \pm 0.003$ & $0.022 \pm 0.014$ \\
\hline $\mathrm{NO}_{3}^{-}-\mathrm{N} /(\mathrm{mg} / \mathrm{kg})$ & $2.01 \pm 1.12$ & $4.61 \pm 0.77$ & $1.50 \pm 0.61$ & $5.58 \pm 3.27$ \\
\hline $\mathrm{NH}_{4}^{+}-\mathrm{N} /(\mathrm{mg} / \mathrm{kg})$ & $7.08 \pm 2.88$ & $9.31 \pm 2.92$ & $15.16 \pm 3.43$ & $20.19 \pm 9.16$ \\
\hline $\mathrm{TOC} /(\mathrm{mg} / \mathrm{kg})$ & $57.84 \pm 27.44$ & $32.71 \pm 12.58$ & $52.85 \pm 11.33$ & $35.47 \pm 26.68$ \\
\hline $\mathrm{TN} /(\mathrm{mg} / \mathrm{kg})$ & $12.06 \pm 0.68$ & $18.33 \pm 16.72$ & $18.64 \pm 3.68$ & $28.90 \pm 8.11$ \\
\hline $\mathrm{TP} /(\mathrm{mg} / \mathrm{kg})$ & $70.00 \pm 29.48$ & $12.80 \pm 1.23$ & $106.60 \pm 8.68$ & $22.01 \pm 7.98$ \\
\hline $\mathrm{C} / \mathrm{N}$ & $11.77 \pm 0.55$ & $11.72 \pm 0.38$ & $12.08 \pm 1.67$ & $11.24 \pm 0.84$ \\
\hline
\end{tabular}

夏季沉积物中 $\mathrm{NH}_{4}^{+}-\mathrm{N}$ 和 $\mathrm{NO}_{3}^{-}-\mathrm{N}$ 含量分别占无机氮总含量的 76.53\% 和 $13.37 \%$, 冬季 $\mathrm{NH}_{4}^{+}-\mathrm{N}$ 含量占无 机氮总含量的比下降到 $77.02 \%$, 而 $\mathrm{NO}_{3}^{-}-\mathrm{N}$ 含量占无机氮总含量的比例上升到 $22.89 \%$.

对北运河水体及沉积物理化指标进行空间差异性分析,结果表明,夏季和冬季中下游沉积物 $\mathrm{NH}_{4}^{+}-\mathrm{N}$ 含 量均显著高于中游 $(P<0.05)$, 而中游沉积物中 $\mathrm{C} / \mathrm{N}$ 均显著高于下游 $(P<0.05)$ (图 2). 季节差异分析发现, 与冬季相比, 夏季沉积物中 TP 含量更高 $(P<0.05)$, 而冬季 $\mathrm{NO}_{3}^{-}-\mathrm{N}$ 含量、TDS 和盐度 (Salinity) 更高 $(P<$ $0.05)$. 除以上指标存在空间和季节性差异之外,其他指标均没有显著差异 $(P>0.05)$.

由于采样点主要位于人类活动干扰大的中游和下游, 大量未经处理的工农业废水和生活污水汇人北运 河, 导致河流污染严重 ${ }^{[18]}$. 北运河中较高含量的 $\mathrm{NH}_{4}^{+} \mathrm{-N}$ 主要来自支流中工业废水的汇人和农田灌溉的输 人,其中凉水河支流的汇人对北运河中 $\mathrm{TN}$ 和 $\mathrm{NH}_{4}^{+}-\mathrm{N}$ 负荷的贡献较大 ${ }^{[15]}$. 有研究表明北运河水体中污染物 质主要来自工业废水的排放, 其次为生活污水和农业面源污染, 下游 $\mathrm{TN}$ 和 $\mathrm{NH}_{4}^{+}-\mathrm{N}$ 负荷主要来自上游及支 流凉水河的共同聚集 ${ }^{[15]}$. 北运河下游汇集了中下游各个支流的河水和岸边农田土壤的径流, 导致沉积物中 $\mathrm{NH}_{4}^{+}-\mathrm{N}$ 累计含量较高. 人类活动及土地利用对河流水体中污染物质的主要存在形态产生了影响.

\section{$2.2 \mathrm{MOB}$ 多样性指标}

北运河夏季和冬季沉积物共扩增 MOB 的基因序列 331 条,序列覆盖范围为 $0.62 \sim 0.88$, 具有代表性. 基 于 2\% 的基因差异, 夏季沉积物 MOB 基因序列共划分出 7 17 个 OTUs, Shannon 多样性指数范围为 0.99 2.51 , Simpson 指数范围为 $0.16 \sim 0.49$; 冬季沉积物 MOB 基因序列共划分出 $3 \sim 15$ 个 OTUs, Shannon 指数范围 为 $0.69 \sim 2.12$, Simpson 指数范围为 $0.13 \sim 0.36$.

沉积物中 MOB 多样指数在空间和季节上均没有显著差异性 $(T$ 检验, $P>0.05)$. 基于 Bray-Curtis 距离, 沉积物中 MOB 的 heatmap 聚类分析显示, MOB 呈现空间和季节聚类的特点, 即中游低氮素样点 $\left(1^{\#} \sim 3^{\#}\right)$ 和 下游高氮素样点 $\left(4^{\#} \sim 7^{\#}\right)$ 分别聚在一起, 且夏季和冬季样点分别聚在一起 (图 3). 温度是影响甲烷好氧氧化 过程的重要环境因子, 温度的变化影响 MOB 的氧化活性, 从而对甲烷气体的传输和释放产生影响 ${ }^{[27]}$.

云南不同土地利用类型的淡水湖泊底泥中 MOB 划分 OTUs 的个数为 $16 \sim 23$, Shannon 指数为 $2.53 \sim$ 


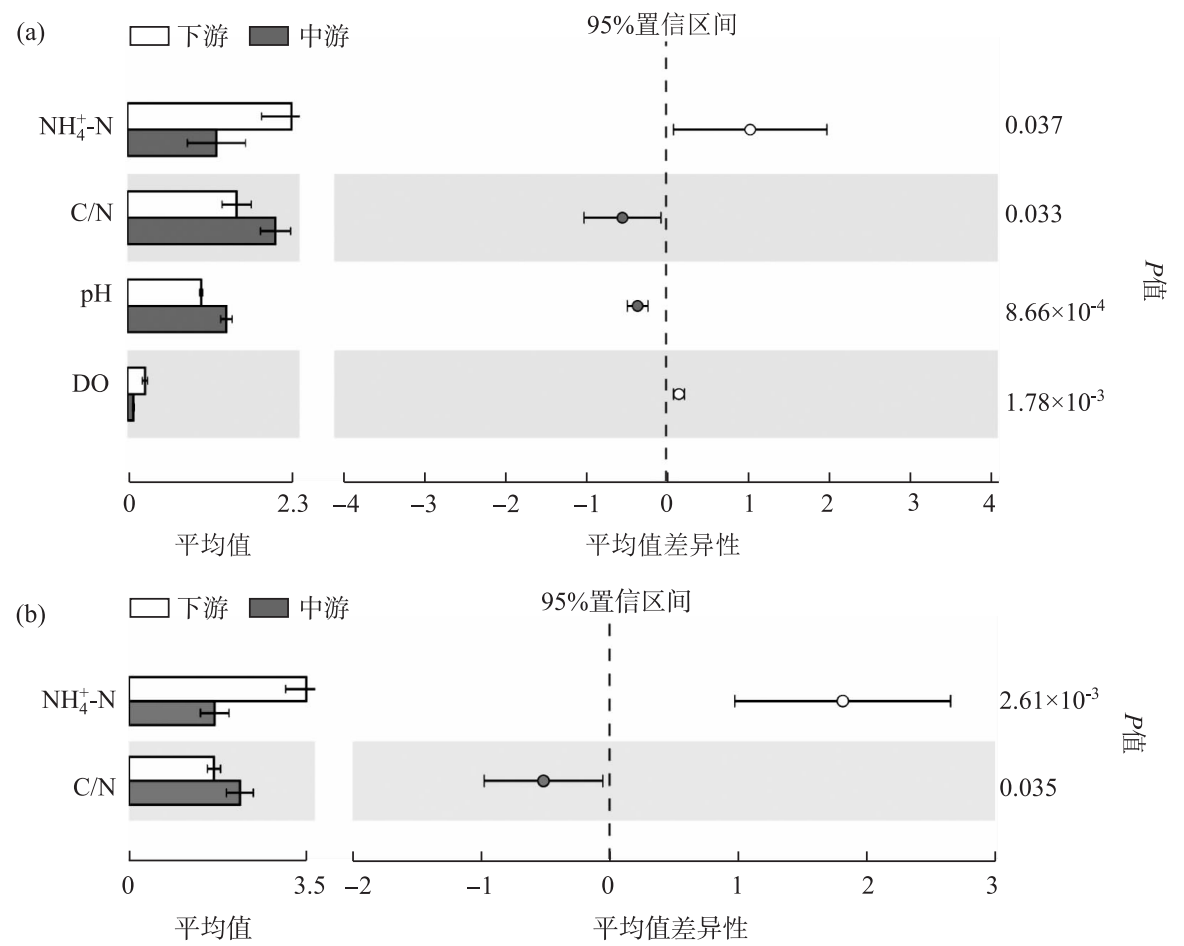

图 2 北运河中、下游夏季 (a) 和冬季 (b) 水体及沉积物理化指标在空间上的差异性

Fig. 2 Differences of nutrient variations in water and sediment between midstream sites and downstream sites in the North Canal ( $a$ : summer, b: winter)

$2.79^{[28]}$. Liu 等 ${ }^{[20]}$ 在中国云南高原 13 个富营养淡水湖泊底泥中发现 MOB 共划分出 $11 \sim 30$ 个 OTUs, Shannon 指数为 2.24 3.12. 北运河沉积物中 MOB 的 OTUs 个数和 Shannon 指数与淡水生态系统相一致 ${ }^{[20]}$. heatmap 的聚类结果与北运河沉积物中氮素的空间差异性一致, 低 $\mathrm{NH}_{4}^{+} \mathrm{-N}$ 含量的中游样点聚在一起, 高 $\mathrm{NH}_{4}^{+}-\mathrm{N}$ 含量的下游样点聚在一起, 沉积物中 $\mathrm{NH}_{4}^{+}-\mathrm{N}$ 含量对 MOB 群落分布有影响.

\section{$2.3 \mathrm{MOB}$ 系统发育树及群落结构差异}

选取 MOB 具有代表性的基因序列进行克隆文库系统发育树分析. 北运河 MOB 共分为 4 个分支,分别 为 Cluster I 、Cluster II 、Cluster III 和 Cluster IV (图 4). 其中 Cluster I 为最大的分支,包括 129 条基因序列,占 据了整个基因序列的 $37.18 \%$, 该分支的基因序列中有 $91.47 \%$ 来自下游样点 $\left(4^{\#} \sim 7^{\#}\right)$,与废水淤泥 ${ }^{[29]}$ 和活性 淤泥 ${ }^{[30]}$ 中 MOB 基因序列有较高的同源性,与来自池塘底泥纯培养的 Methylococcaceae bacterium R-49797 ( I 型 MOB) 有较高的同源性. Cluster II 为第 2 大分支 $27.38 \%$ ), 共 95 条基因序列,该分支的基因序列在中 下游均匀分布 (中游: $46.32 \%$; 下游: $53.68 \%$ ), 与湖泊沉积物 ${ }^{[31]}$ 中 MOB 基因序列的同源性较高. Cluster IV 共有 88 条基因序列 (25.36\%), 该分支的基因序列在中下游均匀分布 (中游:55.68\%; 下游: $44.32 \%$ ), 与来自 稻田土壤以及稻田根际土壤的 MOB 同源性较高, 且与纯培养的 Methylocystis sp. KS30 和 Methylocystis SS2C3 ( II 型 MOB) 也有较高的同源性. Cluster III为最小的分支,包含了 35 个基因序列,占基因序列的 $10.09 \%$,与 湖泊沉积物及湿地土壤来源的相关基因序列的同源性较高, 与纯培养 Methylocystis sp. LW5( II 型 MOB) 有较 高的同源性.

有研究表明,淡水沉积物中 MOB 以 Type I 型的 Methylomonas、Methylobacter 和 Methylosarcina 等属为 主 ${ }^{[9]}$. 对云南 13 个淡水湖泊 ${ }^{[32]}$ 以及美国阿拉斯加北部 Qalluuraq 湖泊 ${ }^{[33]}$ 中 MOB 的研究均发现 Type I 型甲 烷氧化菌是湖泊沉积物中的主要细菌群落. 北运河沉积物中 MOB 以 Type I 型为主. 北运河缺乏自然径流, 主要依靠污水处理厂的再生水补给, 再生水携带设施中的微生物一同汇人北运河, 岸边农田土壤随着雨水 

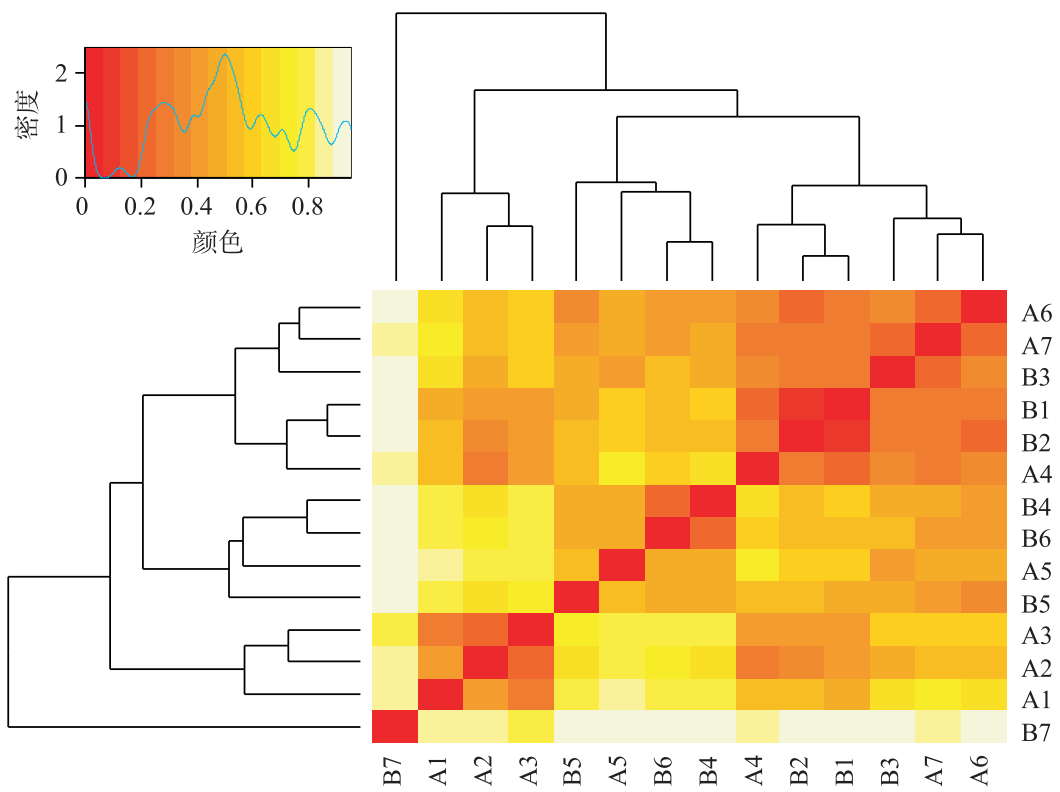

图 3 MOB 的 heatmap 分析

(低氮素样品: $1^{\#} 、 2^{\#}$ 和 $3^{\#}$ 样点; 高氮素样品: $4^{\#} 、 5^{\#} 、 6^{\#}$ 和 $7^{\#}$ 样点; : 夏季; B : 冬季)

Fig.3 Heatmap representing the differences of microbial communities among samples based on Bray-Curtis distance

(Low-nitrogen samples: $1^{\#}, 2^{\#}$ and $3^{\#}$; High-nitrogen samples: $4^{\#}, 5^{\#}, 6^{\#}$ and $7^{\#}$; A: Summer; B: Winter)

汇人河流 ${ }^{[18]}$. 北运河沉积物中 MOB 高同源性菌群主要来自污水处理厂出水和废水淤泥沉积物. 鲍林林 等 ${ }^{[34-35]}$ 对北运河沉积物中的脱氮功能微生物和氨氧化微生物群落特征的研究均表明脱氮功能微生物和氨 氧化微生物均与污水处理厂废水和活性污泥中发现的类群同源性高, 这与本研究中 MOB 群落的相关研究 结果一致. 农田土壤中有关 MOB 的研究表明, II 型 MOB 占主导地位 ${ }^{[28]}$. MOB 的系统发育树 Cluster III分支 中 MOB 高同源性菌群的来源与该分支样点污染物的来源一致.

\section{$2.4 \mathrm{MOB}$ 共存网络关系结构}

共存网络关系结构 (Co-occurrence Network) 可以用来评估复杂生态系统中微生物之间的相互关系 ${ }^{[36-37]}$, 描述栖息地环境特征与微生物群落之间的聚集关系 ${ }^{[38-39]}$. 网络结构拓扑图中点的分布及点与点之间的相互 关系能影响系统的稳定性 ${ }^{[39-40]}$.

通过 Pearson 相关性分析, 选取 MOB 相关关系显著的 OTUs $(P<0.05)$, 构建拓扑结构图. 空间上, 中游共 16 个显著相关的节点, 26 条相关线 (图 5a); 下游显著相关的节点共 38 个, 相关线 120 条 (图 5b), 同上游的 网络关系相比, 下游集聚系数更高, 特征路径更长, 网络关系较复杂, 与氮素有显著相关的 OTU 个数较多. 季 节上, 夏季 OTUs 的网络结构图中共有 25 个显著相关的节点, 72 条相关线 (图 6a); 冬季有显著相关的节点 38 个, 相关线 100 条 (图 6b). 两季节网络结构的异质性程度和模块化程度均较高. 夏季的网络结构集中化 程度和网络结构的集聚系数高于冬季的相应参数. 与冬季的聚类程度相比, 夏季聚为 3 类, 其中一部分聚集 规模较大, 聚集程度较强, 该部分 $\mathrm{OTUs}$ 主要受 $\mathrm{NH}_{4}^{+}-\mathrm{N}$ 和 $\mathrm{NO}_{3}^{-}-\mathrm{N}$ 的共同影响.

模块化程度 (modularity) $>0.4$ 表明网络拓扑图已经形成模块化 ${ }^{[41]}$, 更高的模块化程度反映出更强的生 态位分化程度 ${ }^{[39]}$, 生态位的分化程度越高, 其为物种提供的生态位越多 ${ }^{[22-43]}$. 北运河中游和下游、夏季和冬 季 OUTs 的模块化程度均较高, 因此空间和季节变化对 MOB 群落的生态位分化影响较小. 网络结构参数中 的聚集系数 (clustering coefficient) 及特征路径长度 (characteristic path length) 表征网络关系图中节点与节点 之间紧密联系的程度 ${ }^{[44]}$, 一般而言聚集系数越大, 节点彼此之间的联系越紧密, 相关关系线越短 ${ }^{[43,45]}$, 物种 之间相关关系越紧密, 受到环境变化的干扰程度越高 ${ }^{[42,46]}$. 与中游的 OTUs 聚集系数相比, 下游的集聚系数 


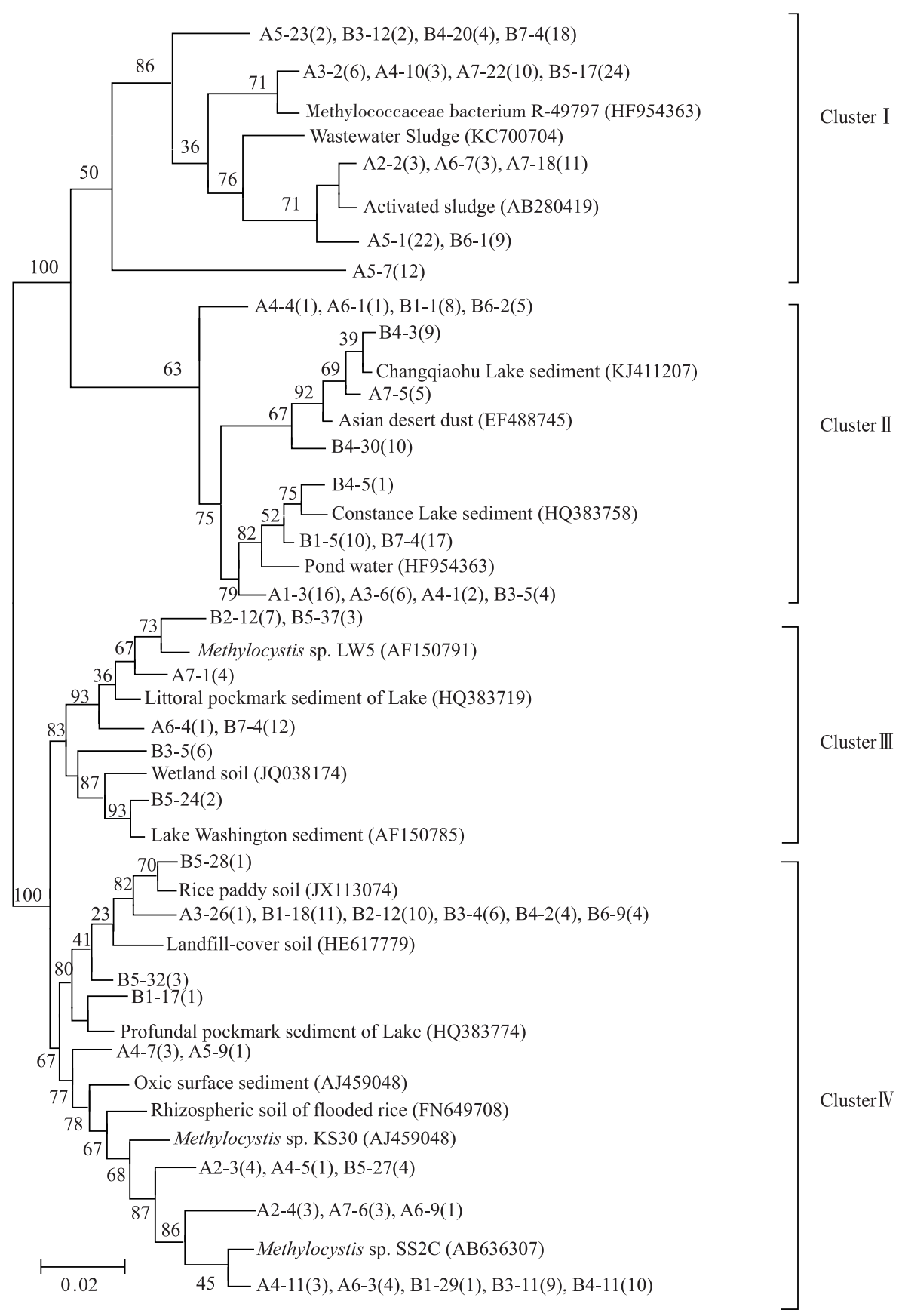

图 4 北运河沉积物中 MOB 基因序列的系统发育树

Fig.4 Phylogenetic tree of representative $p m o A$ sequences and reference sequences from GenBank in the North Canal

更高, 表明沉积物中 MOB 对环境变化的敏感程度有空间变化特征, 下游沉积物中 MOB 对环境变化更敏感. 而 MOB 在夏季和冬季的集聚系数均较高, 表明季节变化对微生物群落的聚集程度影响较小 (表 2). 共现网 络结构图可以表征物种与环境因子之间的正负关系, 表征 OTUs 与环境因子之间联系的紧密程度 ${ }^{[44]}$. 北运 河 MOB 的共现网络结构图中 (图 5), OTUs 与氮素之间的联系程度存在空间差异性, 这与沉积物中氮素的空 
间差异性一致. 有研究表明,外源氮对 MOB 氧化作用的影响主要依赖于环境中氮的存在形态 ${ }^{[9]}$. 因此, MOB 与环境因子的联系程度依赖于北运河沉积物中氮素的主要存在形态.

(a)

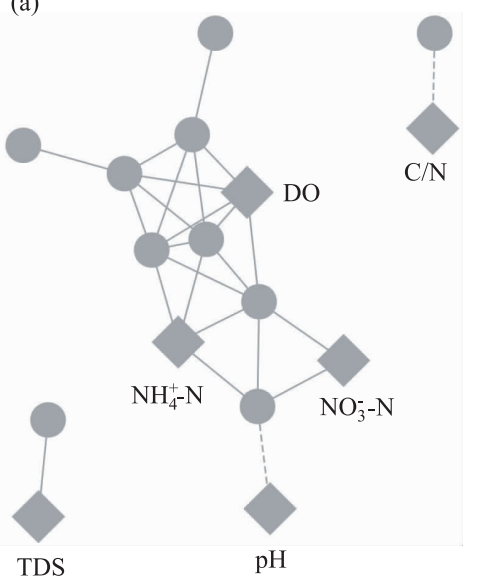

(b) $\mathrm{pH}$

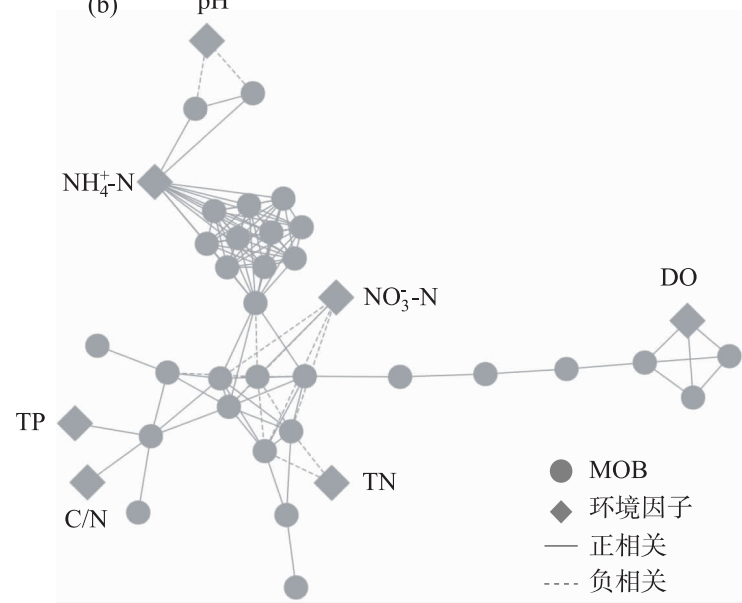

图 5 北运河中游 (a) 和下游 (b) MOB 的 co-occurrence network 分析 (线段代表相关性, 只有 $P<0.05$ 的相关关系在图中显示,下同)

Fig.5 The co-occurrence network of MOB bacteria communities in midstream (a) and downstream (b) of the North Canal (Line segments represent correlation; only strong and significant relationships ( spearman $r>0.7, P<0.05$ ) are shown; The same below)

(a)

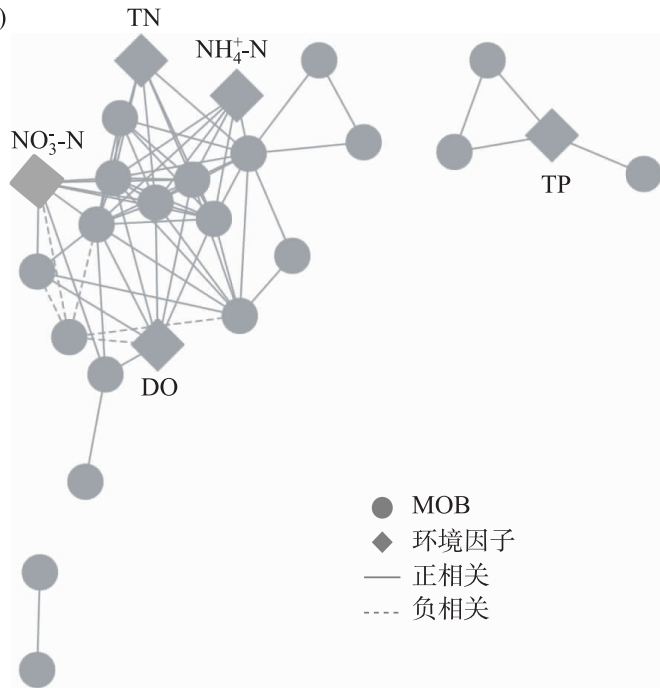

(b)

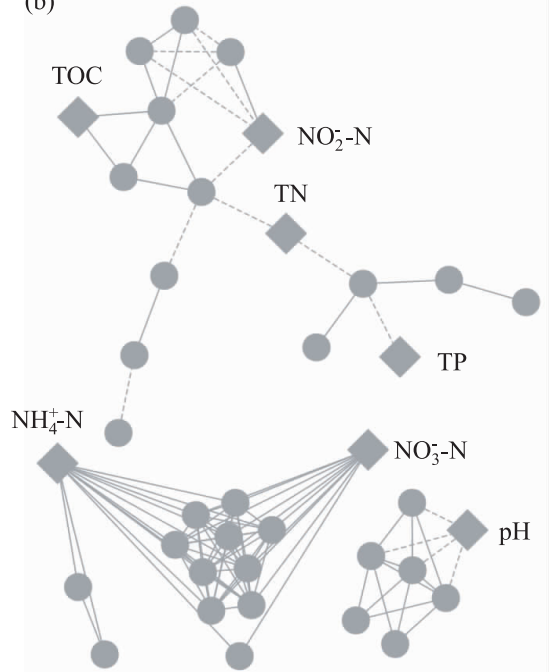

图 6 北运河夏季 (a) 和冬季 (b) MOB 的 co-occurrence network 分析

Fig.6 The co-occurrence network of MOB bacteria communities in summer (a) and winter (b) in the North Canal

\section{5 北运河 MOB 群落结构与环境因子响应关系}

根据 Pearson 相关性分析 (表 3), MOB 的生物多样性指标与 $\mathrm{NH}_{4}^{+}-\mathrm{N} 、 \mathrm{NO}_{3}^{-}-\mathrm{N}$ 和 $\mathrm{NO}_{2}^{-}-\mathrm{N}$ 、 $\mathrm{TN}$ 及 $\mathrm{TOC}$ 有显 著的相关关系 $(P<0.05)$, 其中 $\mathrm{NO}_{2}^{-}-\mathrm{N} 、 \mathrm{NH}_{4}^{+}-\mathrm{N}$ 与 $\mathrm{MOB}$ 的系统发育树 Cluster I 分支相关关系显著. 外源氮素 的添加通过改变 MOB 生长所需要的有机营养物质对其生物多样性产生影响 ${ }^{[4]}$. 结合系统发育树分析结果, Cluster I 为 MOB 最大的分支, 其高同源性菌群主要来自生物反应器和废水淤泥, 有研究表明北, 运河中的 
$\mathrm{NH}_{4}^{+}-\mathrm{N}$ 主要来自生活废水和工业废水的排放 ${ }^{[15]}$. 因此, 北运河中高含量 $\mathrm{NH}_{4}^{+}-\mathrm{N}$ 的来源影响了沉积物中 MOB 的来源.

表 2 北运河 MOB 共存关系拓扑结构参数

Tab.2 Topological parameters of microbial network of MOB in the North Canal

\begin{tabular}{lcccc}
\hline 拓扑结构参数 & 中游 & 下游 & 夏季 & 冬季 \\
\hline 网络直径 & 5 & 10 & 5 & 7 \\
网络集中度 & 0.219 & 0.221 & 0.332 & 0.194 \\
网络异质性 & 0.668 & 0.657 & 0.689 & 0.665 \\
特征路径长度 & 2.074 & 3.701 & 1.815 & 2.355 \\
集聚系数 & 0.363 & 0.620 & 0.612 & 0.600 \\
模块性 & 0.632 & 0.633 & 0.58 & 0.575 \\
\hline
\end{tabular}

表 $3 \mathrm{MOB}$ 多样性指标与环境因子的 Pearson 相关性

Tab.3 Pearson's correlations between microbial pmoA diversity of MOB and environment factors

\begin{tabular}{lcccccr}
\hline 多样性指标 & $\mathrm{DO}$ & $\mathrm{NO}_{2}^{-}-\mathrm{N}$ & $\mathrm{NO}_{3}^{-}-\mathrm{N}$ & $\mathrm{NH}_{4}^{+}-\mathrm{N}$ & $\mathrm{TN}$ & $\mathrm{TOC}$ \\
\hline OTUS & 0.55 & -0.19 & $0.61^{*}$ & $-0.81^{* *}$ & -0.02 & 0.01 \\
Shannon & 0.68 & $-0.52^{*}$ & 0.46 & $-0.72^{* *}$ & -0.12 & -0.02 \\
Simpson & -0.25 & $0.74^{*}$ & 0.47 & $0.64^{*}$ & $0.61^{*}$ & $0.53^{*}$ \\
Chao1 & 0.45 & -0.21 & $0.61^{*}$ & 0.15 & 0.05 & 0.12 \\
Clusters I & -0.64 & $0.55^{*}$ & 0.20 & $0.62^{*}$ & 0.05 & 0.11 \\
Clusters II & 0.01 & 0.34 & -0.26 & 0.14 & 0.11 & 0.01 \\
Clusters III & 0.67 & 0.11 & 0.19 & 0.07 & 0.17 & 0.19 \\
Clusters IV & $0.80^{*}$ & 0.01 & -0.05 & $0.52^{*}$ & -0.34 & -0.29 \\
\hline
\end{tabular}

*表示在 0.05 水平上显著相关; $* *$ 表示在 0.01 水平上显著相关;其他无显著相关.

CCA 分析进一步探讨 MOB 群落分布与氮素的响应关系 (图 7). CCA 分析的轴 1 和轴 2 的解释变量分 别为 $46.51 \%$ 和 $29.74 \%$, 前两轴的总解释变量为 $76.25 \%$. 依据 Monte Carlo 检验, 选择 6 个与解释轴有强相关 的环境因子, 其中 $\mathrm{TDS}(0.99) 、$ Salinity $(0.98) 、 \mathrm{NO}_{3}^{-}-\mathrm{N}(0.97) 、 \mathrm{NH}_{4}^{+}-\mathrm{N}(0.95)$ 和 $\mathrm{TN}(0.88)$ 均与轴 1 有显著相关 关系, $\mathrm{NO}_{2}^{-}-\mathrm{N}(0.98)$ 与轴 2 有显著相关关系. 北运河夏季和冬季样点基本分布在轴 1 , 与 $\mathrm{NH}_{4}^{+}-\mathrm{N} 、 \mathrm{NO}_{3}^{-}-\mathrm{N}$ 等环 境因子有强响应关系. 依据 Mantel 检验(表 4), $\mathrm{NH}_{4}^{+}-\mathrm{N}$ 和 TN 对沉积物中 MOB 群落分布有显著影响 $(r>0.4$, $P<0.01)$, 而 $\mathrm{NO}_{3}^{-}-\mathrm{N}$ 和 $\mathrm{NO}_{2}^{-}-\mathrm{N}$ 对 $\mathrm{MOB}$ 群落分布没有显著相关性 $(P>0.05)$. Mantel 检验的结果证明, 环境中 氮素的主要存在形态对 MOB 群落分布的影响显著.

生态系统中外源氮素的输人对 MOB 的氧化有抑制作用,抑制作用的强弱主要依赖于氮素的主要存在 形态和浓度水平 ${ }^{[48-49]}$. 农田氮肥的施用, 尤其是 $\mathrm{NH}_{4}^{+}$会对 $\mathrm{MOB}$ 的氧化起抑制作用, 降低甲烷的氧化速 率 ${ }^{[13,50-53]}, \mathrm{NH}_{4}^{+}$的抑制作用主要通过与甲烷竞争甲烷氧化酶系统相同的位点, 减少甲烷氧化酶的有效性途径 来抑制 MOB 对甲烷的氧化 ${ }^{[13,52]}$. 本研究中 $\mathrm{NH}_{4}^{+}-\mathrm{N}$ 为北运河沉积物中氮素的主要形态, $\mathrm{NH}_{4}^{+}-\mathrm{N}$ 和 $\mathrm{NO}_{3}^{-}-\mathrm{N}$ 均 对 MOB 的群落特征有显著影响, 且 $\mathrm{NH}_{4}^{+}-\mathrm{N}$ 的影响作用强于 $\mathrm{NO}_{3}^{-}-\mathrm{N}$ 的影响作用. 有研究表明, 不同氮素形态 对甲烷的氧化作用产生不同的影响, 与相同含量的 $\mathrm{NO}_{3}^{-}-\mathrm{N}$ 相比, $\mathrm{NH}_{4}^{+}-\mathrm{N}$ 对甲烷氧化速率的抑制作用更强, 本 文与其研究结果一致. $\mathrm{NH}_{4}^{+}-\mathrm{N}$ 对甲烷化氧化的抑制率与其在环境中的含量呈正相关关系 ${ }^{[51,54]}$. 北运河由于 受到人类活动的影响, 加剧了 $\mathrm{NH}_{4}^{+}-\mathrm{N} 、 \mathrm{NO}_{3}^{-}-\mathrm{N}$ 和 $\mathrm{NO}_{2}^{-}-\mathrm{N}$ 的汇人, 扩大了对 $\mathrm{MOB}$ 群落结构及其来源的影响, 进 一步影响了 $\mathrm{MOB}$ 对甲烷的氧化过程. 外源 $\mathrm{NH}_{4} \mathrm{Cl}$ 和 $\mathrm{NH}_{4} \mathrm{NO}_{3}$ 的输人除了抑制甲烷的氧化作用外, 还分别使 甲烷产生速率提高了 $136.7 \%$ 和 $136.55 \%{ }^{[55]}$. 因此, 研究城市河流中高含量的 $\mathrm{NH}_{4}^{+}-\mathrm{N}$ 对甲烷产生及消耗影响 是控制河流温室气体排放的关键. 


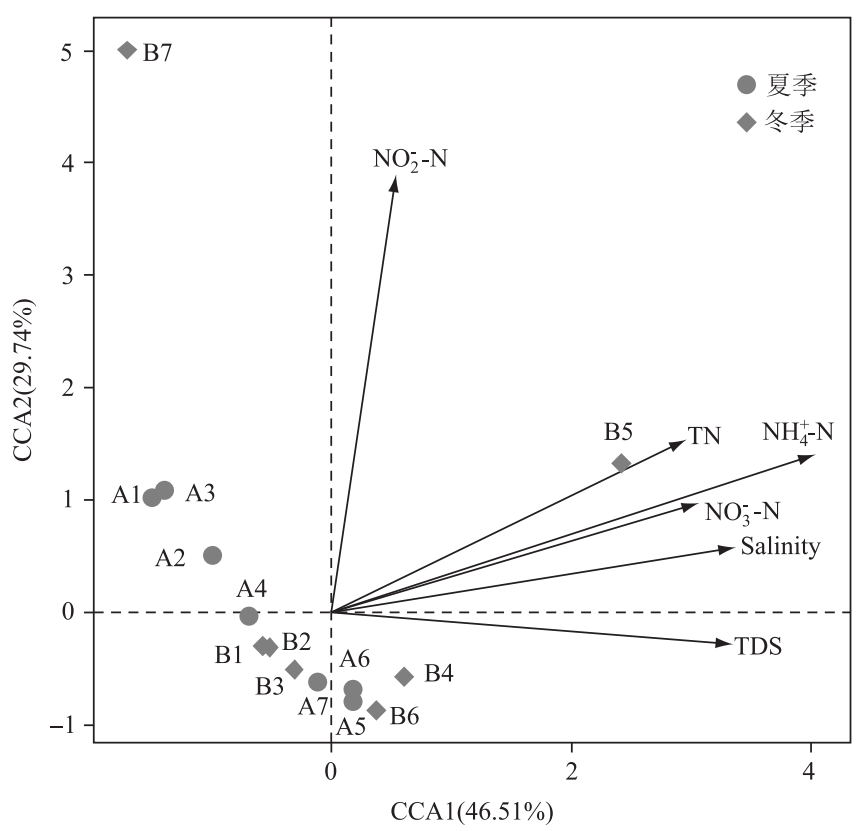

图 7 北运河 $\mathrm{MOB}$ 与环境因子的 RDA 分析

Fig.7 The correlation analysis between MOB with environmental factors in the North Canal

表 4 MOB 群落组成与环境因子

相关关系的 Mantel 检验

Fig.4 Mantel correlations highlight the relationships between environmental trait and MOB community composition

\begin{tabular}{ccl}
\hline 环境因子 & Mantel score $(r)$ & \multicolumn{1}{c}{$P$} \\
\hline $\mathrm{NH}_{4}^{+}-\mathrm{N}$ & 0.407 & $0.004^{* *}$ \\
$\mathrm{NO}_{3}^{-}-\mathrm{N}$ & 0.101 & 0.346 \\
$\mathrm{NO}_{2}^{-}-\mathrm{N}$ & 0.610 & 0.061 \\
$\mathrm{TN}$ & 0.574 & $0.005^{* *}$ \\
$\mathrm{TDS}$ & 0.183 & $0.017^{*}$ \\
Salinity & 0.399 & $0.010^{*}$ \\
\hline
\end{tabular}

*表示在 0.05 水平上显著相关, ***表示在 0.01 水平上显著相关,其他无显著相关.

\section{3 结论}

北运河沉积物中 $\mathrm{NH}_{4}^{+}-\mathrm{N}$ 为氮素的主要形态, 其存在显著 的空间差异性, 下游沉积物中 $\mathrm{NH}_{4}^{+}-\mathrm{N}$ 含量显著高于上游. $\mathrm{NH}_{4}^{+}-\mathrm{N}$ 含量的变化对 MOB 群落的空间分布有影响, $\mathrm{NH}_{4}^{+}-\mathrm{N}$ 含 量的空间分布特征与 MOB 的群落聚类特征一致.

北运河 $\mathrm{NH}_{4}^{+}-\mathrm{N}$ 的来源影响了 $\mathrm{MOB}$ 的系统发育和 $\mathrm{MOB}$ 的主要菌种, $\mathrm{MOB}$ 高同源性菌群来源与 $\mathrm{NH}_{4}^{+}-\mathrm{N}$ 的来源一致, 其在系统发育树各分支中的主导菌种与 $\mathrm{NH}_{4}^{+}-\mathrm{N}$ 的来源中主 要菌种一致.

MOB 的 OTUs 之间联系的紧密程度依赖于北运河沉积物 中氮素的主要存在形态及其含量水平. $\mathrm{NH}_{4}^{+}-\mathrm{N}$ 含量较高的下 游沉积物中 MOB 的 OTUs 之间相关关系更强, 其对环境变化 更敏感,受到环境变化干扰的影响程度更高.

氮素对 MOB 的影响主要依赖于氮素在环境中的主要存在形态. 北运河沉积物 $\mathrm{NH}_{4}^{+}-\mathrm{N}$ 与 MOB 群落分布 有显著的响应关系, 是沉积物中 MOB 群落分布的主要影响因素.

\section{4 参考文献}

[ 1 ] Wang XF, Yuan XZ, Chen $\mathrm{H}$ et al. Review on $\mathrm{CO}_{2}$ and $\mathrm{CH}_{4}$ Emissions from Rivers. Environmental Science, 2017,38 (12) : 5352-5366. [王晓锋, 袁兴中, 陈槐等. 河流 $\mathrm{CO}_{2}$ 与 $\mathrm{CH}_{4}$ 排放研究进展. 环境科学, 2017, 38 (12): 5352-5366.

[ 2 ] Butman D, Raymond PA. Significant efflux of carbon dioxide from streams and rivers in the United States. Nature Geoscience, $2011,4(12): 839-842$. 
[ 3 ] Marie ADA, Marvin DL. Methane in surface waters of oregon estuaries and rivers. Limnology and Oceanography, 1987, 32 (3) : 716-722.

[ 4 ] Stanley EH, Casson NJ, Christel ST et al. The ecology of methane in streams and rivers: patterns, controls, and global significance. Ecological Monographs, 2016, 86(2) : 146-171.

[ 5 ] Le MJ, Roger P. Production, oxidation, emission and consumption of methane by soils: a review. European Journal of Soil Biology, 2001, 37(1) : 25-50.

[ 6 ] Wang J, Song YH, Peng JF et al. Spatial-temporal distribution and community structure analysis of nitrite-dependent anaerobic methaneoxidizing bacteria in the sediments of the Hun River. Research of Environmental Sciences, 2015, 28(11): 1670-1676. [王佳, 宋永会, 彭剑峰等. 浑河底泥反硝化厌氧甲烷氧化菌群落结构时空特征. 环境科学研究, 2015, 28(11) : 1670-1676.]

[ 7 ] Patrick JM, Ashley MH, Suzanne MT. Stream denitrification across biomes and its response to anthropogenic nitrate loading. Nature, 2008, 452 (7184) : 202-205.

[ 8 ] Jacob DH, Owen TM, Catherine MF et al. Dissolved organic matter quality and bioavailability changes across an urbanization gradient in headwater streams. Environment Science and Technology, 2014, 48(14) : 7817-7824.

[ 9 ] Yun JL, Wang YF, Zhang HX. Ecology of aerobic methane oxidizing bacteria (methanotrophs). Acta Ecologica Sinica, 2013, 33(21) : 6774-6785. [贠娟莉, 王艳芬, 张洪勋. 好氧甲烷氧化菌生态学研究进展. 生态学报, 2013, 33 (21) : 6774-6785.]

[10] Charlotte S, Peter K. Environmental factors influencing attenuation of methane and hydrochlorofluorocarbons in landfill cover soils. Journal of Environmental Quality Abstract-Bioremediation and Biodegradation, 2004, 33(1) : 72-79.

[11] Shen L, Liu S, Zhu Q et al. Distribution and diversity of nitrite-dependent anaerobic methane-oxidising bacteria in the sediments of the Qiantang River. Environmental Microbiology, 2014, 67(2) : 341-349.

[12] Ding WX, Cai ZC. Effect of nitrogen fertilizers on methane oxidation in soils by methanotrophs. Chinese Journal of Eco-Agriculture, 2003, 11(2) : 50-53. [丁维新, 蔡祖聪. 氮肥对土壤氧化甲烷的影响研究. 中国生态农业学报, 2003,11 (2) : 50-53.]

[13] Wang ZP, Hu CS, Yang JR. Effect of inorganic nitrogen on $\mathrm{CH}_{4}$ oxidation in soils. Chinese Journal of Applied Ecology, 2003, 14(2) : 305-309. [王智平, 胡春胜, 杨居荣. 无机氮对土壤甲烷氧化作用的影响. 应用生态学报, 2003,14 (2) : 305-309.]

[14] Jing HW, Zhang ZG, Guo J. Water pollution characteristics and pollution sources of Bei Canal river system in Beijing. China Environmental Science, 2013, 33(2): 319-327. [荆红卫, 张志刚, 婧郭. 北京北运河水系水质污染特征及污染来 源分析. 中国环境科学, 2013, 33(2): 319-327.]

[15] Chen YJ, Pang SJ, Geng RZ et al. Fluxes of the main contaminant in Beiyun River. Acta Scientiae Circumstantiae, 2015, 35(7) : 2167-2176. [陈永娟, 庞树江, 耿润哲等. 北运河水系主要污染物通量特征研究. 环境科学学报, 2015, 35 ( 7 ) : 2167-2176.]

[16] Dan D. Analysis of degradation coefficient in North Canal [Dissertation]. Beijing: Captal Normal University, 2013. [单 铎. 北运河氨氮降解系数测算研究 [学位论文]. 北京: 首都师范大学, 2013.]

[17] Zhang WS, Li XX, Wang XY. Temporal and spatial variations of water pollution in Wuqing section of Beiyunhe River. Acta Scientiae Circumstantiae, 2012, 32(4): 836-846. [张汪寿, 李晓秀, 王晓燕. 北运河武清段水污染时空变异特征. 环境科学学报, 2012, 32(4): 836-846.]

[18] Du Y, Hu WX, Wang XY et al. Concentrations of chemical oxygen demand fractions and their biodegradability in waters of Beiyun River, Beijing. Wetland Science, 2017, (3) : 470-477. [杜伊, 胡玮璇, 王晓燕等. 北京市北运河水体中化学 需氧量组分含量及其可生化性研究. 湿地科学, 2017, (3) : 470-477.]

[19] Bao SD ed. Analusis of soil agronomization. Beijing: China Agriculture Press, 2010. [鲍士旦. 土壤农化分析. 北京: 中 国农业出版社, 2010.]

[20] Liu Y, Zhang J, Zhao L et al. Aerobic and nitrite-dependent methane-oxidizing microorganisms in sediments of freshwater lakes on the Yunnan Plateau. Applied Microbiology and Biotechnology, 2015, 99(5) : 2371-2381.

[21] Schloss PD, Westcott SL, Ryabin T et al. Introducing mothur: Open-source, platform-independent, community-supported software for describing and comparing microbial communities. Applied and Environmental Microbiology, 2009, 75 ( 23): 7537-7541. 
[22] Tamura K, Dudley J, Nei M et al. MEGA4: Molecular Evolutionary Genetics Analysis (MEGA) software version 4.0. Molecular Biology and Evolution, 2007, 24(8) : 1596-1599.

[23] Parks D, Tyson G, Hugenholtz P et al. STAMP: Statistical analysis of taxonomic and functional profiles. Bioinformatics, 2014, (30): 3123-3124.

[24] Revelle W. Psych: Procedures for personality and psychological research, Northwestern University, Evanston, Illinois, $\mathrm{USA}[\mathrm{CP} / \mathrm{OL}]$. Https ://CRAN.R-project.org/package = psych.

[25] Assenov Y, Ramirez F, Schelhorn S et al. Computing topological parameters of biological networks. Bioinformatics, 2008, (24) : 282-284.

[26] Oksanen J, Blanchet F, Friendly M et al. Vegan: Community ecology package. R package version 2.4-3[ CP/OL]. Https: //CRAN.R-project.org/package = vegan.

[27] Wang WQ. Methane emission in reed marsh of Minjiang River Estuary and the discussing of environmental influencing factors [Dissertation]. Fujian: Fujian Normal University, 2008. [王维奇. 闽江河口芦苇湿地甲烷排放及其主要环境影 响因子分析 [学位论文]. 福建: 福建师范大学, 2008.]

[28 ] Dai Y, Wu Z, Xie S et al. Methanotrophic community abundance and composition in plateau soils with different plant species and plantation ways. Applied Microbiology and Biotechnology, 2015, 99(21) : 9237-9244.

[29] Adrian H, Siegfried EV, Katharina FE et al. Revisiting methanotrophic communities in sewage treatment plants. Applied and Environmental Microbiology, 2013, 79(8) : 2841-2846.

[30] Dong J, Ding L, Wang X et al. Vertical profiles of community abundance and diversity of Anaerobic Methanotrophic Archaea (ANME) and bacteria in a simple waste landfill in North China. Applied Biochemstry Biotechnology, 2015, 175 ( 5 ) : 2729-2740.

[31] Laanbroek HJ. Methane emission from natural wetlands_ interplay between emergent macrophytes and soil microbial processes. A mini-review. Annals of Botany, 2010, 105(1) : 141-153.

[32] Wang Y, Zhu G, Harhangi HR et al. Co-occurrence and distribution of nitrite-dependent anaerobic ammonium and methane-oxidizing bacteria in a paddy soil. FEMS Microbiology Letter, 2012, 336: 79-88.

[33] He R, Wooller MJ, Pohlman JW et al. Diversity of active aerobic methanotrophs along depth profiles of arctic and subarctic lake water column and sediments. The ISME Journal, 2012, (6) : 1937-1948.

[34] Bao LL, Wang XY, Chen YJ et al. Diversity, abundance and distribution of nir S-type denitrifiers and anammox bacteria in sediments of Beiyun River. China Environmental Science, 2016, 36(5) : 1520-1529. [鲍林林, 王晓燕, 陈永娟等. 北运河沉积物中主要脱氮功能微生物的群落特征. 中国环境科学, 2016, 36 (5) : 1520-1529.]

[35] Bao LL, Chen YJ, Wang XY. Diversity and abundance of ammonia-oxidizing prokaryotes in surface sediments in Beiyun River. China Environmental Science, 2015, 35(1): 179-189. [ 鲍林林, 陈永娟, 王晓燕. 北运河沉积物中氨氧化微 生物的群落特征. 中国环境科学, 2015, 35(1): 179-189.]

[36] Gotelli NJ, Mccabe DJ. Species co-occurrence: A meta-analysis of J. M. Diamond's Assembly Rules Model. Ecology, 2002, 83(8) : 2091-2096.

[37] Fuhrman J. Microbial community structure and its functional implications. Nature, 2009, 459(7244) : 193-199.

[38] Barberan AS, Bates E, Casamayor NF. Using network analysis to explore co-occurrence patterns in soil microbial communities. ISME Journal, 2012, (6) : 343-351.

[39] Freedman Z, Zak D. Atmospheric N deposition alters connectance, but not functional potential among saprotrophic bacterial communities. Molecular Ecolofy, 2015, 24(12) : 3178-3180.

[40] Barberan A, Bates ST, Casamayor EO et al. Using network analysis to explore co-occurrence patterns in soil microbial communities. Isme J, 2012, (6) : 343-351.

[41] Newman ME. Modularity and community structure in networks. P Natl Acad Sci Usa, 2006, 103(23) : 8577-8582.

[42] Montoya JM, Pimm SL, Sole RV. Ecological networks and their fragility. Nature, 2006, 442(7100) : 259-264.

[43] Zhao D, Shen F, Zeng J et al. Network analysis reveals seasonal variation of co-occurrence correlations between Cyanobacteria and other bacterioplankton. Science of the Total Environment, 2016, 573: 817-825.

[44] de Menezes AB, Prendergast-Miller MT, Richardson AE et al. Network analysis reveals that bacteria and fungi form modules that correlate independently with soil parameters. Environment Microbiology, 2015, 17( 8) : 2677-2689.

[45] Cram JA, Xia LC, Needham DM et al. Cross-depth analysis of marine bacterial networks suggests downward propagation of 
temporal changes. The ISME Journal, 2015, (9) : 2573-2586.

[46] Saavedra S, Stouffer DB, Uzzi B et al. Strong contributors to network persistence are the most vulnerable to extinction. $N a$ ture, 2011, 478(7368) : 233-235.

[47] Zhang JC, Xu YQ, Lu YH. Icrobial mechanisms of methane production and oxidation in terrestrial ecosystems. Acta Ecologica Sinica, 2015, (20): 6592-6603. [张坚超, 徐镱钦, 陆雅海. 陆地生态系统甲烷产生和氧化过程的微生物机 理. 生态学报, 2015, (20): 6592-6603.]

[48] Shrestha M, Shrestha PM, Frenzel P et al. Effect of nitrogen fertilization on methane oxidation, abundance, community structure, and gene expression of methanotrophs in the rice rhizosphere. The ISME Journal, 2010, (4) : 1545-1556.

[49] Roland FAE, Darchambeau FO, Morana CD et al. Nitrous oxide and methane seasonal variability in the epilimnion of a large tropical meromictic lake (Lake Kivu, East-Africa). Aquat Sci, 2017, 79(2) : 209-218.

[50] Mosier A, Schimel D, Valentine D et al. Methane and nitrous oxide fluxes in native, fertilized and cultivated grasslands. Nature, 1991, 350(6316): 330-332.

[51] Fu L, Ding J, Lu Y et al. Nitrogen source effects on the denitrifying anaerobic methane oxidation culture and anaerobic ammonium oxidation bacteria enrichment process. Environmental Biotechnology, 2017, 101(9) : 3895-3906.

[52] Yang SS, Chen IC, Ching PL. Carbon dioxide and methane emissions from Tanswei River in Northern Taiwan. Atmospheric Pollution Research, 2015, 6(1) : 52-61.

[53] Qi RJ, Chen JX, Dan JG. Effects of exogenous nitrogen on methane oxidation in upland soils of different types in northern Hainan Island. Chinese Journal of Tropical Crops, 2016, (8): 1534-1539. [齐润杰, 陈金霞, 但建国. 外源氮对琼北 不同类型土壤甲烷氧化能力的影响. 热带作物学报, 2016, (8) : 1534-1539.]

[54] Van der Nat FWA, DE Brouwer JFC, Middelburg JJ et al. Spatial distribution and inhibition by ammonium of methane oxidation in intertidal freshwater marshes. Applied and Environmental Microbiology, 1997, 63(12) : 4734-4740.

[55] Hu MJ, Zou FF, Ren P et al. Effects of nitrogen and sulfate additions on methane production and oxidation in the Min River estuarine marsh. Acta Ecolofy Sinica, 2017, (1) : 167-176. [胡敏杰, 邹芳芳, 任鹏等. 闽江河口湿地土壤 $\mathrm{CH}_{4}$ 产 生与氧化速率对外源氮、硫添加的响应. 生态学报, 2017, (1): 167-176.] 